\title{
A case report of secondary infection by Vibrio splendidus associated with gas bubble disease in syngnathid fishes (Syngnathus schlegeli and Hippocampus haema)
}

\author{
Gyoungsik Kang, Kwang-Min Choi, Min-Soo Joo, Won-Sik Woo, Chan-II Park \\ Department of Marine Biology and Aquaculture, College of Marine Science, Gyeongsang National University, Tongyeong 53064, Korea
}

\begin{abstract}
Seahorses, which have been cultivated since the 2000s, are economically very important. Gas bubble disease (GBD) is a significant concern in the cultivation of seahorses; therefore, this study aimed to determine the cause of GBD-induced death in two species of Syngnathidae (Syngnathus schlegeli and Hippocampus haema). Rod-shaped bacteria were observed histopathologically and identified as Vibrio splendidus by conventional and real-time PCR analyses. The lethality of $V$. splendidus varies depending on the host's immune status, and the disease can be prevented through water quality management or improvement of the breeding environment. In this study, the GBD lesions (gas bubbles) were observed at $12^{\circ} \mathrm{C}, 8.0 \mathrm{mg} / \mathrm{L}$ of dissolved oxygen, $30 \mathrm{ppt}$ of salinity, and pH 7.7. In addition, rod-shaped bacteria, infiltration of inflammatory cells, and extensive serous exudate were confirmed in the lesions where gas bubbles were found. PCR analysis was able to detect $V$. splendidus, possibly a secondary infection of the immunocompromised syngnathid fish. Understanding the risk of immunity control and the correlation between these lesions and causal agents will be of great help to the aquaculture industry and the ornamental fish market.
\end{abstract}

Keywords: Vibrio splendidus, Gas bubble disease, Syngnathus schlegeli, Hippocampus haema

\section{Introduction}

Vibrio sp. can infect various aquatic animals and of them, $V$. splendidus is known to cause high mortality in larvae and juveniles of mollusks such as carpet shell clams (Ruditapes decussatus), oysters (Crassostrea gigas and C. virginica), and great scallop (Pecten maximus) (Gómez-León et al., 2005; Lacoste et al., 2001a; Lambert et al., 1999; Waechter et al., 2002). V. splendidus also infects the larvae of cod (Godus morhua) and turbot (Scophthalmus maximus) (Gatesoupe et al., 1999; Reid et al., 2009 ). V. splendidus infection in seahorses was reported in 2009 (Balcázar et al., 2010). In the first report, seahorses had disease

Received: Sep 8, 2021 Revised: Oct 7, 2021 Accepted: Nov 23, 2021

${ }^{\star}$ Corresponding author: Chan-Il Park

Department of Marine Biology and Aquaculture, College of Marine Science, Gyeongsang National University, Tongyeong 53064, Korea Tel: +82-55-772-9153, Fax: +82-55-772-9159, E-mail: vinus96@hanmail.net

This is an Open Access article distributed under the terms of the Creative Commons Attribution Non-Commercial License (http://creativecommons.org/licenses/by$\mathrm{nc} / 4.0 /$ ) which permits unrestricted non-commercial use, distribution, and reproduction in any medium, provided the original work is properly cited.

Copyright $\odot 2022$ The Korean Society of Fisheries and Aquatic Science 
symptoms such as lethargy, lack of appetite, white spots on the skin and necrotic tail lesions caused by both Vibrio alginolyticus and V. splendidus (Balcázar et al., 2010). In particular, V. splendidus is a ubiquitous microorganism in seawater and has been frequently isolated from marine fish and invertebrates (Thompson et al., 2004).

These Vibrio sp. infections can be fatal when the immune system is weak; the correlation between stress or stress-induced hormones and an animal's immune resistance suggests the importance of mechanical and/or physiological management (Bricelj et al., 1992; Lacoste et al., 2001a; Lacoste et al., 2001b). Furthermore, excessive $\mathrm{CO}_{2}$ concentrations can induce the acidification of water and it can be negatively affect host immunity against $V$. splendidus infection (Cao et al., 2018a). In addition, as do most cultured fishes, seahorses become stressed when maintained at high densities and that stress makes them more vulnerable to infection (Sanaye et al., 2013). From this point of view, water quality management can reduce the damage caused by Vibrio sp. infections, but such physical/physiological management is not easy. Thus, it is necessary to identify pathogens from clinical symptoms and gross pathology (lesions) in the early stages of the disease to improve survival rates.

Seahorse aquaculture has developed rapidly since 2000 in some countries due to commercial trades and their unique morphology, their remarkable camouflage ability and the distinctive phenomenon whereby males give birth to live young (LePage et al., 2015; Zhang et al., 2015). For many years, seahorses have been collected from the wild for curiosity, exhibition in aquariums and traditional medicine (Jiang et al., 2020; Lepage et al., 2015). A suggested alternative to wild-caught animals is animals maintained in captive culture or aquaculture (Lepage et al., 2015). For commercial seahorse aquaculture, the growth and survival of newborn seahorses is still a challenge, even though many scientific studies have been conducted (Zhang et al., 2015). Among various factors, gas bubble disease (GBD) is regarded as a major health issue for seahorses, and research on disease control is required and ongoing (LePage et al., 2015; Zhang et al., 2015).

Generally, GBD is divided into two types by the target organs. First, the air bubbles found in the digestive tract usually occur in juvenile rearing by live food organisms (Sanaye et al., 2013). When the seahorse juveniles occur GBD, gas bubbles exhibit irregular swimming patterns, lose their balance, leading to starvation and ultimately to death. Second, the seahorse has external gas bubbles by environmental problems such as oxy- gen and nitrogen level or by bacterial infections where carbon dioxide produced by the bacteria becomes trapped underneath the skin (Sanaye et al., 2013). These gas bubbles may occur anywhere on the head and body of the seahorse and can cause stress on a seahorse as problems with buoyancy and movement arise (LePage et al., 2015; Sanaye et al., 2013). The treatment, darkening the tank's background, increasing the oxygen saturation to $4 \mathrm{ppm}$ or more, or using acetazolamide has been reported (Sanaye et al., 2013). GBD is believed to be caused by either bacterial infection or gas supersaturation in the water column, though this remains unresolved (Sanaye et al., 2013).

GBD can occur in any life cycle of the seahorse and may cause problems such as a decrease in growth rate, especially during the juvenile period (Zhang et al., 2015). Furthermore, multiple infections have been reported in various cases with GBD (LePage et al., 2015).

Our laboratory confirmed that GBD occurred in several tanks where seahorses were raised. The death of the whole seahorses raised in one tank occurred, and molecular biological and histopathological examinations were performed to determine the cause of death.

\section{Materials and methods}

\section{Fish}

Two species of Syngnathidae (5 Syngnathus schlegeli and 5 Hippocampus haema) were bred in the same $120 \mathrm{~L}$ aquarium maintained at $12{ }^{\circ} \mathrm{C}$. The dissolved oxygen was maintained full aeration $(8 \pm 0.3 \mathrm{mg} / \mathrm{L}), 30 \pm 0.4 \mathrm{ppt}$ of salinity, and $\mathrm{pH}$ was 7.7 \pm 0.1 . All fish died within two weeks after gas bubble formation, and the one with the best condition for each species was used for biomass measurement. The Syngnathus schlegeli had a whole-body length of $20.3 \mathrm{~cm}$ and a bodyweight of $2.8 \mathrm{~g}$. The other species, H. haema, had a whole-body length of $5.9 \mathrm{~cm}$ and a body weight of $3.3 \mathrm{~g}$ (Fig. 1).

\section{Biopsy and bacterial isolation}

To determine the bacterial infection associated with GBD, all samples $(n=10)$ of the skin lesions (bubbles) were harvested and incubated at $27^{\circ} \mathrm{C}$ in brain heart infusion agar (BHIA, BD Difco, Fraklin Lakes, NJ, USA). In addition, the gill, kidney, skin, and spleen of each sample were tested for parasitic infection and pathogen identification.

Single colonies in BHI agar were subcultured in BHI broth for 1 day at $27^{\circ} \mathrm{C}$ for the identification of the cultured bacteria. 
(A)

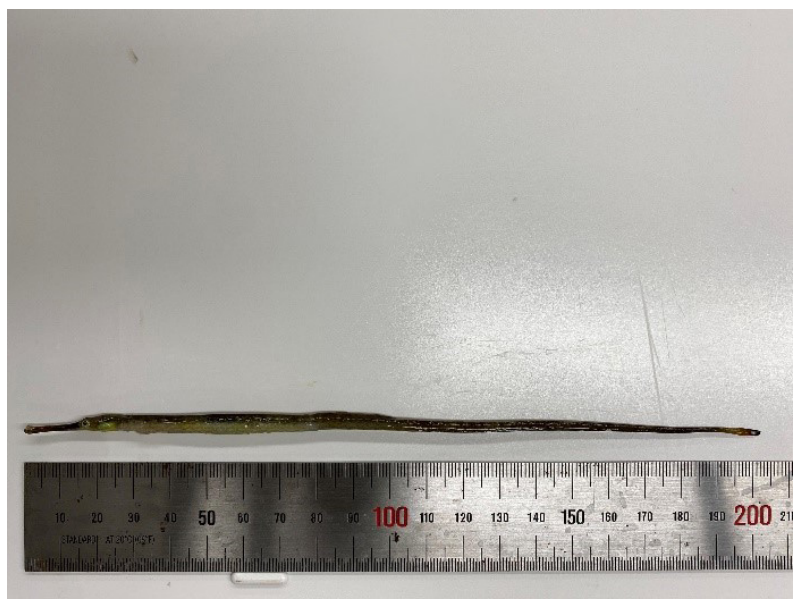

(B)

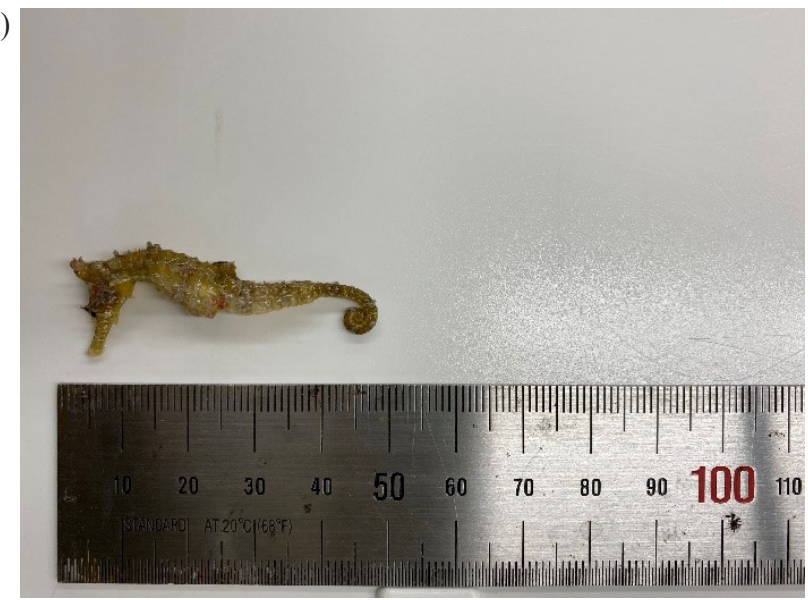

Fig. 1. The external appearances of the two species of Syngnathidae. (A) Syngnathus schlegeli, (B) Hippocampus haema.

For direct sequence analysis to identify the species, the sequences of samples were read using the $27 \mathrm{~F}$ universal primer for bacteria.

\section{Histopathological analysis}

Histopathological analysis was performed on the whole body because of the size of the samples. Each sample was fixed in $10 \%$ neutral-buffered formalin for 3 days after prefixation for decalcification in Bouin's solution for 5 days. After fixation, the whole body samples were collected and refixed in the same solution for 1 day before being gradually dehydrated with ethanol series (50\%-100\%). The samples were further cleared using xylene, after which, the samples were embedded in paraffin wax and sectioned into slices of $4 \mu \mathrm{m}$ thickness. Finally, the sections were stained with hematoxylin-eosin (H\&E) and Giemsa following routine protocols.

\section{DNA extraction, polymerase chain reaction (PCR), and se- quence analysis}

Genomic DNA of the two species of Syngnathidae was extracted using an AccuPrep ${ }^{\varpi}$ genomic DNA extraction kit (Bionner, Daejeon, Korea) following the manufacturer's guidelines. Homogenized kidney, spleen, and skin samples were used for polymerase chain reaction (PCR) to detect bacterial infection and to identify the exact species. All the genomic DNA samples were stored at $-80^{\circ} \mathrm{C}$ until further analysis. PCR was performed using universal bacterial primers and universal primers for the 16S rRNA gene of the mitochondrial DNA (mtDNA) to identify the host species (Ivanova et al., 2007; Takahashi et al., 2014). Briefly, $10 \mu \mathrm{L}$ of Exprime Taq Premix (GeNet Bio, Nonsan,
Korea), $7 \mu \mathrm{L}$ of distilled water, $1 \mu \mathrm{L}$ of genomic DNA, and $1 \mu \mathrm{L}$ each of forward and reverse primer were mixed. In addition, real-time PCR was performed to identify $V$. splendidus accurately (Saulnier et al., 2017). The sequences of primers and PCR conditions are displayed in Table 1.

Before sequence analysis, amplicons were extracted by a QIAquick $^{\circledast}$ gel extraction kit (Qiagen, Hilden, Germany) following the manufacturer's protocol. The purified PCR products were cloned into a pGEM $^{\circledR}$ T-easy vector (Promega, Madison, WI, USA) and transformed into Escherichia coli JM109 competent cells according to a standard protocol. After full propagation, plasmid DNA was extracted using a Hybrid-Q ${ }^{\mathrm{Tm}}$ plasmid rapidprep kit (GeneAll ${ }^{\oplus}$, Seoul, Korea) and sequenced using the universal M13 primer set. Nucleotide sequence matching was performed for the identification of bacteria and hosts using the basic local alignment search tool (BLAST) algorithm of the National Centre for Biotechnology Information (https://blast.ncbi. nlm.nih.gov/blast).

\section{Results}

\section{Gross pathology of the lesions}

Five S. schlegeli and H. haema each were sampled, and all of them died two weeks after the first occurrence of GBD. In macroscopic observation, both species of Syngnathidae had edema of the epidermis filled with edematous exudate. Briefly, S. schlegeli and H. haema had bubbles all over their bodies, especially $H$. haema, which had lesions and a reddish anus, a common sign of pathogen infection in fish (Fig. 2). As these 
Table 1. Base sequence information and polymerase chain reaction (PCR) conditions for the primer set used in this study

\begin{tabular}{|c|c|c|c|c|c|}
\hline Target & Primer & Title 2 & PCR conditions & Length of seq. & Reference \\
\hline \multirow[t]{2}{*}{$\begin{array}{l}\text { Prokaryote } 16 \mathrm{~S} \\
\text { rRNA }\end{array}$} & Pro341F & $\begin{array}{l}\text { AATGATACGGCGACCACCGAGATCTA- } \\
\text { CACTCTTTCCCTACACGACGCTCTT- } \\
\text { CCGATCTCCTACGGGAGGCAGCAG- } \\
\text { CCTACGGGNBGCASCAG }\end{array}$ & \multirow{2}{*}{$\begin{array}{l}95^{\circ} \mathrm{C} \text { for } 3 \mathrm{~min} \text {, followed by } 28 \mathrm{cycles} \\
\text { of denaturation at } 95^{\circ} \mathrm{C} \text { for } 30 \mathrm{sec} \text {, } \\
\text { annealing at } 55^{\circ} \mathrm{C} \text { for } 30 \mathrm{sec} \text {, and } \\
\text { extension at } 72^{\circ} \mathrm{C} \text { for } 30 \mathrm{sec} \text {, and } \\
\text { final extension of } 5 \mathrm{~min} \text { at } 72^{\circ} \mathrm{C}\end{array}$} & \multirow[t]{2}{*}{550} & \multirow[t]{2}{*}{$\begin{array}{l}\text { Takahashi et al. } \\
\text { (2014) }\end{array}$} \\
\hline & Pro805R & $\begin{array}{l}\text { CAAGCAGAAGACGGCATAC- } \\
\text { GAGATNNNNNNGTGACTG- } \\
\text { GAGTTCAGACGTGTGCTCTT- } \\
\text { CCGATCTGACTACNVGGG- } \\
\text { TATCTAATCC }\end{array}$ & & & \\
\hline Vibrio splendidus & $\begin{array}{l}16 \mathrm{~S} \mathrm{SpF2} \\
16 \mathrm{~S} \mathrm{SpR2} \\
16 \mathrm{~S} \text { probe }\end{array}$ & $\begin{array}{l}\text { ATCATGGCTCAGATTGAACG } \\
\text { CAATGGTTATCCCCCACATC } \\
\text { FAM } \\
\text { CCCATTAACGCACCCGAAGGATTG } \\
\text { BHQ1 }\end{array}$ & $\begin{array}{l}95^{\circ} \mathrm{C} \text { for } 10 \mathrm{~min} \text {, and followed by } 40 \\
\text { Cycles of } 15 \mathrm{sec} \text { at } 95^{\circ} \mathrm{C} \text { and } 90 \mathrm{sec} \text { at } \\
60^{\circ} \mathrm{C}\end{array}$ & 150 & $\begin{array}{l}\text { Saulnier et al. } \\
\text { (2017) }\end{array}$ \\
\hline $\begin{array}{l}\text { Mitochondrial 16S } \\
\text { rRNA }\end{array}$ & $\begin{array}{l}16 \text { Sar-5' } \\
16 \text { Sbr-3' }\end{array}$ & $\begin{array}{l}\text { CGCCTGTTTATCAAAAACAT } \\
\text { CCGGTCTGAACTCAGATCACGT }\end{array}$ & $\begin{array}{l}94^{\circ} \mathrm{C} \text { for } 2 \mathrm{~min} \text {, followed by } 35 \mathrm{cycles} \\
\text { of denaturation at } 94^{\circ} \mathrm{C} \text { for } 30 \mathrm{sec} \text {, } \\
\text { annealing at } 52^{\circ} \mathrm{C} \text { for } 40 \mathrm{sec} \text {, and } \\
\text { extension at } 72^{\circ} \mathrm{C} \text { for } 1 \mathrm{~min} \text {, and final } \\
\text { extension of } 10 \mathrm{~min} \text { at } 72^{\circ} \mathrm{C}\end{array}$ & $550-600$ & $\begin{array}{l}\text { Ivanova et al. } \\
\qquad(2007) ; \\
\text { Palumbi (1996) }\end{array}$ \\
\hline
\end{tabular}

(A)

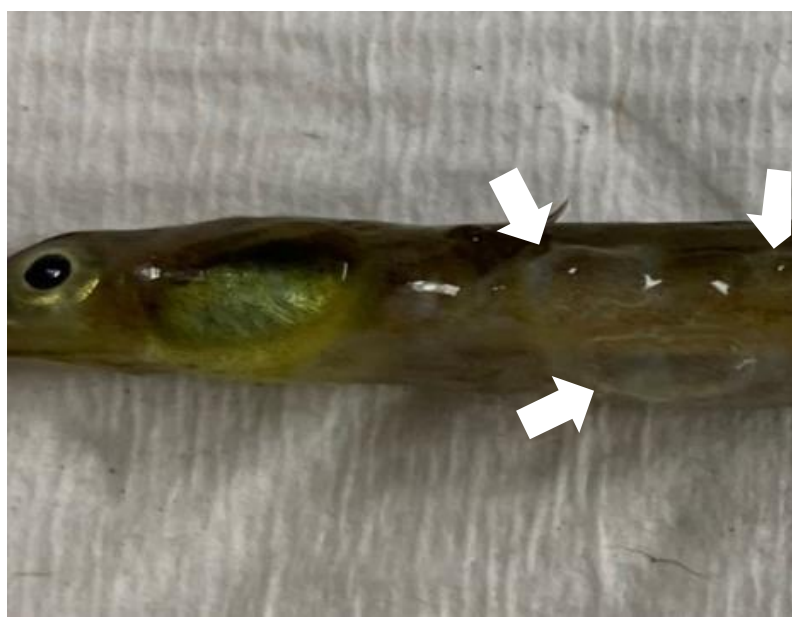

(B)

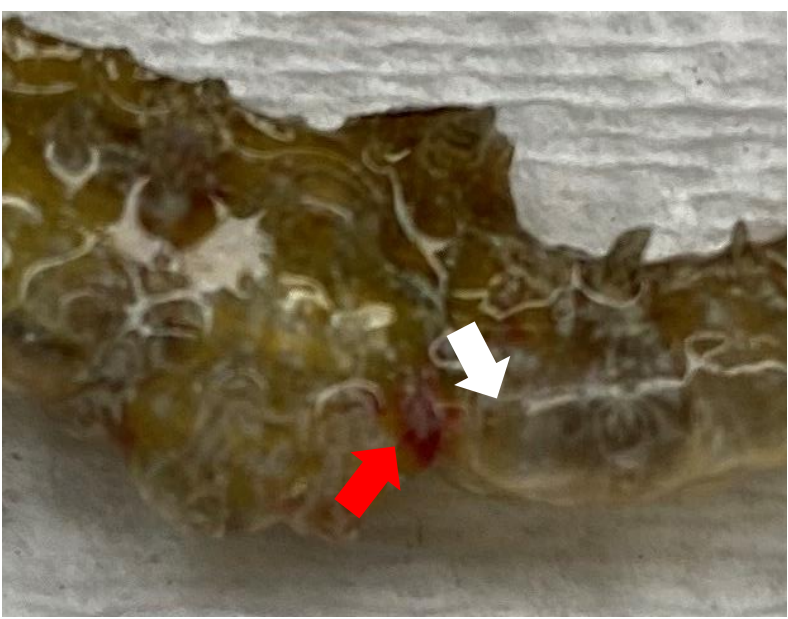

Fig. 2. Gross pathology of the lesions. bubbles, white arrows; reddish anus, a red arrow. (A) Syngnathus schlegeli, (B) Hippocampus haema.

lesions appeared after a certain amount of time (1 week) post-bubbles-creation, it is reasonable to consider them as gross pathology caused by secondary $V$. splendidus infection rather than GBD.

\section{Biopsy and bacterial isolation}

As a result of culturing bacteria from the exudates of the lesions in the BHI agar, bacterial colonies appeared in 5 out of 5
S. schelegeli and 3 out of $5 \mathrm{H}$. haema. Dominant colonies were sub-cultured in BHI broth, and transferred to PCR analysis. Any visible parasites were not observed by light microscopy.

\section{Histopathological analysis}

Histopathologically, rod-shaped bacteria, infiltration of inflammatory cells, formation of melano macrophage centers (MMCs), and extensive serous exudate were observed in integumental 
lesions (Figs. 3 and 4). Other organs (gill, intestine, kidney, liver, spleen, etc.) were unremarkable. Infectious pathogens such as parasites and virus could not be identified.

\section{Polymerase chain reaction (PCR) and sequence analysis}

Ribosomal RNA (rRNA) nucleotide sequencing was performed for all samples $(n=10)$ using universal primers to detect prokaryotes in the lesions (skin) (Takahashi et al., 2014). V. splendidus was confirmed in conventional PCR and real-time PCR analysis of all samples via electrophoresis with 550 and 150 bp PCR products, respectively (Fig. 5A, 5B). PCR analysis and Sanger sequencing of both the species of Syngnathidae identified the host fish species (GenBank accession number of
S. schlegeli: OK398128 and GenBank accession number of $H$. haema: OK398127) (Fig. 5C). As a result of culturing bacteria in the BHI agar, V. splendidus was not isolated from 2 out of 5 samples (H. haema), but V. splendidus infection was confirmed in all samples by conventional, and real-time PCR and sequences of all samples $(n=10)$ were showed $97.31 \%-98.3 \%$ homology with $V$. splendidus type strain (GenBank accession number: MT445179). The most homologous sequence data obtained after the culture and PCR amplification of V. splendidus-infected samples $(\mathrm{n}=8)$ were deposited in GenBank (accession number: MZ452983).

(B)

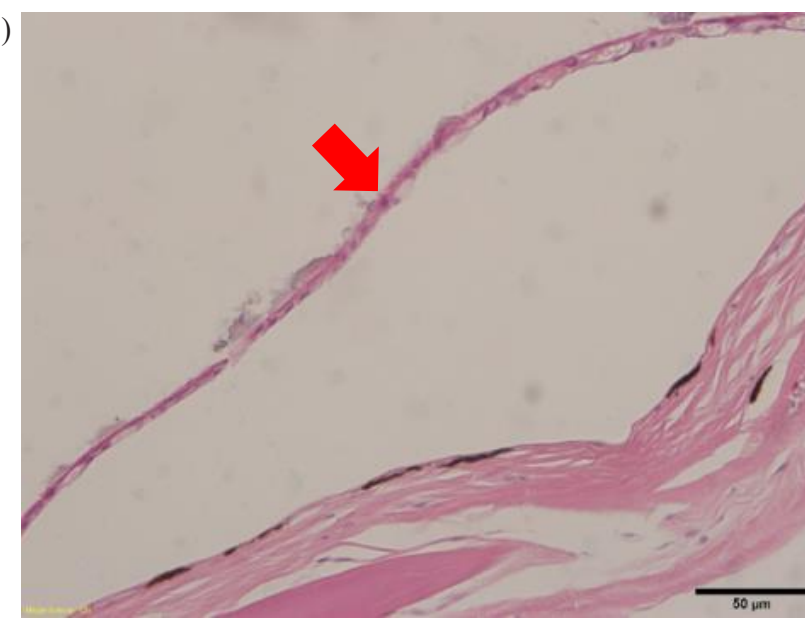

(D)

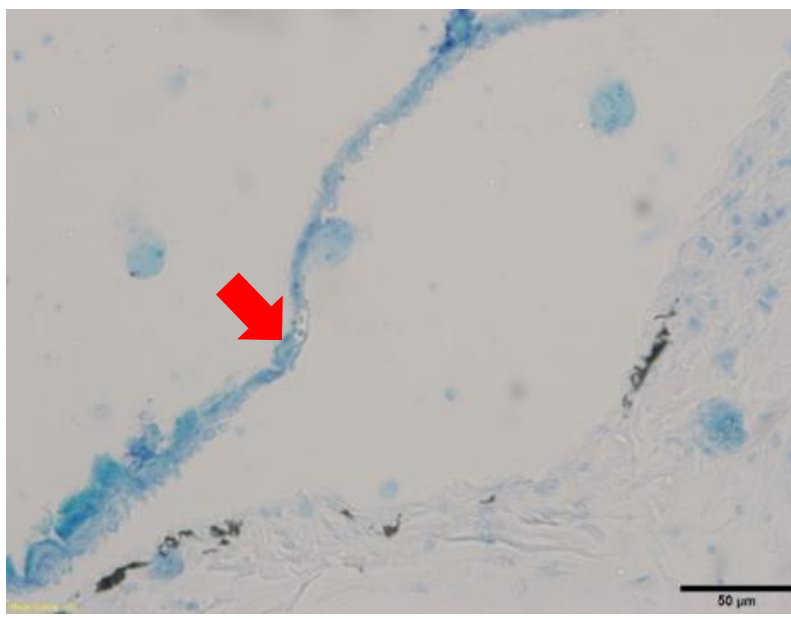

(C)

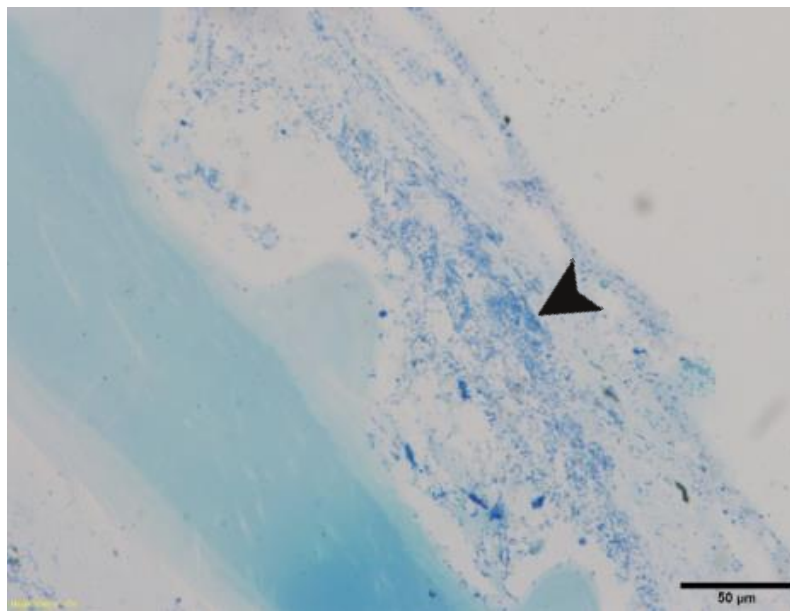

(A)

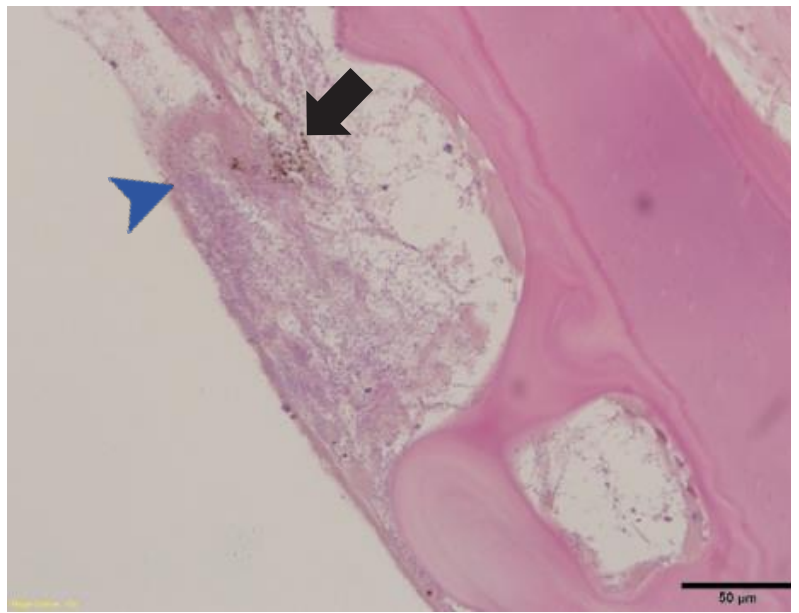

Fig. 3. Histopathological analysis of skin from Syngnathus schlegeli and Hippocampus haema positively infected with Vibrio splendidus. Melano macrophage centers (MMCs), a black arrow; epithelial cells removed by air bubbles, red arrows; extensive serous exudate, a blue arrowhead; infiltration of inflammatory cells, a black arrowhead. H\&E staining of (A) skin of S. schlegeli and (B) skin of $H$. haema. Giemsa staining of (C) skin of S. schlegeli and (D) skin of H. haema. Scale bar $=50 \mu \mathrm{m}$. 
(A)

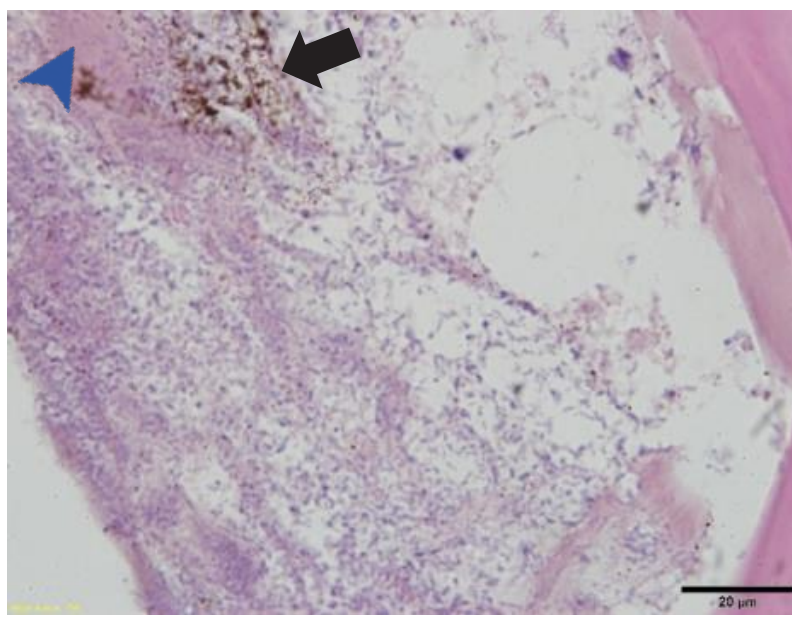

(B)

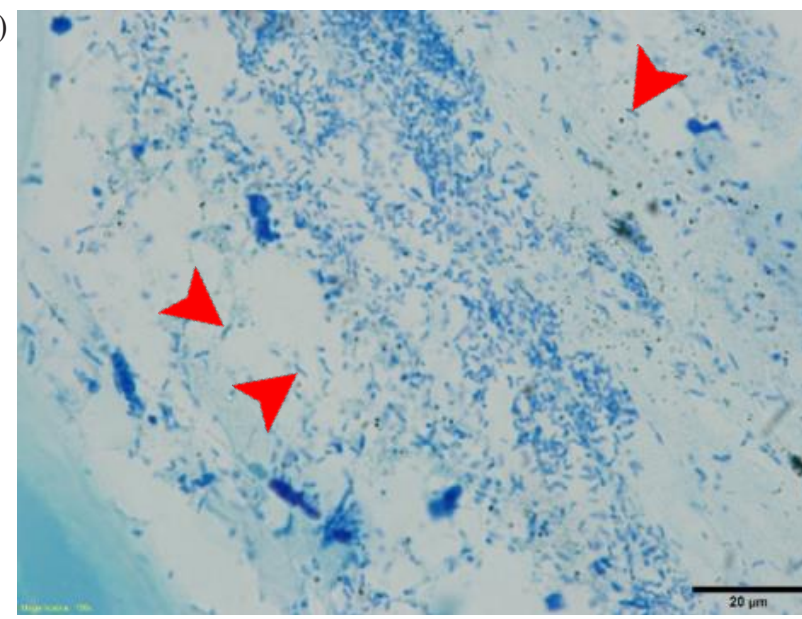

Fig. 4. Histopathological analysis of skin from Syngnathus schlegeli positively infected with Vibrio splendidus at high magnification. Melano macrophage centers (MMCs), a black arrow; extensive serous exudate, a blue arrowhead; rod-shaped bacteria, red arrowheads. H\&E staining of (A) skin of S. schlegeli. Giemsa staining of (B) skin of S. schlegeli. Scale bar $=20 \mu \mathrm{m}$.

\section{Discussion}

In V. splendidus-induced secondary infection in other species of seahorses, disease symptoms (lethargy, lack of appetite, and white spots on the skin) similar to those of gas bubbles have been observed (Balcázar et al., 2010). However, a reddish anus was only observed in $H$. haema, which is similar to necrotic tail lesions of H. guttulatus and H. hippocampus (Balcázar et al., 2010). These differences can be due to the different host species (Syngnathus and Hippocampus) or strains of the infectious pathogens. Moreover, considering that the aquarium was managed at $12{ }^{\circ} \mathrm{C}$, which is close to the appropriate water temperature of $10^{\circ} \mathrm{C}$ for $V$. splendidus, it can be seen that the decrease in immunity due to GBD affects the sensitivity to environmental bacterial pathogens (Armada et al., 2003; Liu et al., 2016).

The reason for these diseases could be acidification due to the accumulation of $\mathrm{CO}_{2}$ because of poor water exchange (Cao et al., 2018a; Cao et al., 2018b). However, despite identifying pathogens from dead individuals (first occurrence), changing the amount of water exchanged to improve the water quality, the remaining individuals died within two weeks. Although GBD can be caused by environmental or physical problems (such as an increase in the dissolved gas pressure above the ambient air pressure and supersaturation) (Sanaye et al., 2013), secondary infection with $V$. splendidus was observed in this study is thought to be related with death after the GBD. In addition, from dead individuals, clear rod-shaped bacteria were observed in the histopathological analysis, and molecular biological data supported V. splendidus as the cause of death. According to Sanaye et al. (2013), GBD can be caused by bacteria of the epidermis, and infection by $V$. splendidus has shown white spots (presumed to be gross pathology lesions caused by large amounts of inflammatory cells infiltrating the bubbled area) in other species (Balcázar et al., 2010).

Jiang et al. (2020) suggested Pseudoalteromonas spongiae as the cause of tail necrosis observed in the tail rot disease of another seahorse species, $H$. kuda. However, in the present study, only H. haema showed necrotic lesions in the anus, suggesting that the gross pathology may differ depending on the type of infectious pathogen or host species.

Identifying the causative agent of infectious disease is always required, but distinguishing aquatic diseases is relatively more difficult than distinguishing diseases among other vertebrates in many cases. Therefore, the methods for diagnosing aquatic diseases depend on molecular-biological analyses, such as PCR , quantitative PCR, loop mediated isothermal amplification (LAMP), and so on (Pires et al., 2020). Specified pathogen detection has reduced costs and a short inspection period. However, detection analysis can identify a wide range of pathogens and can help to identify pathogens associated with disease of unknown etiology, although it identifies an incomprehensive range of agents. From this point of view, studying the relationship between gross pathology and infectious disease agent is very important for both of the aquaculture industry and the 
(A)

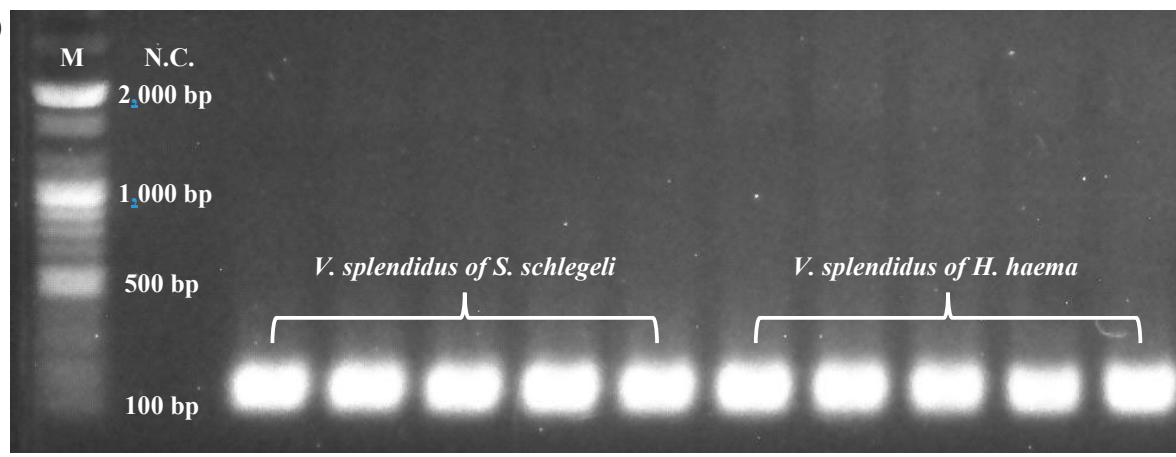

(B)

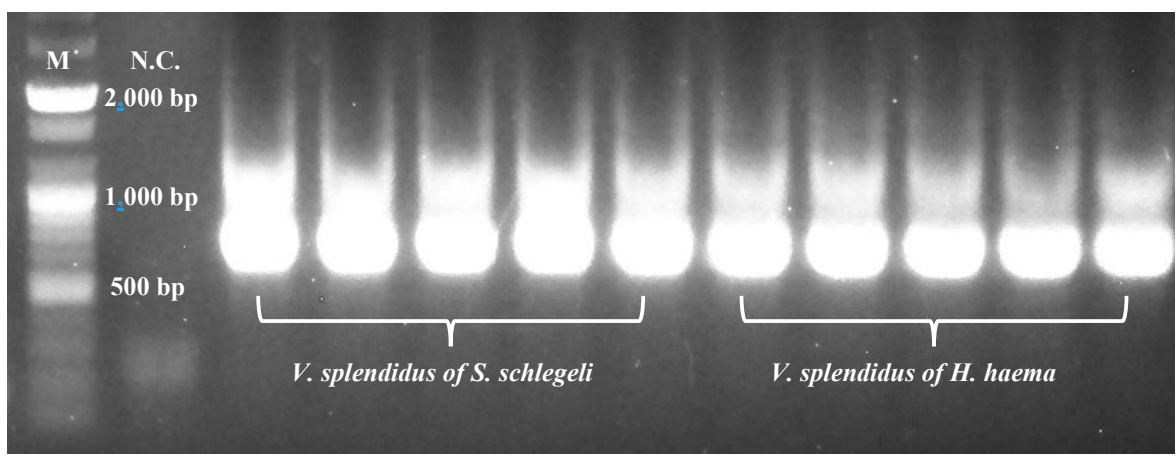

(C)

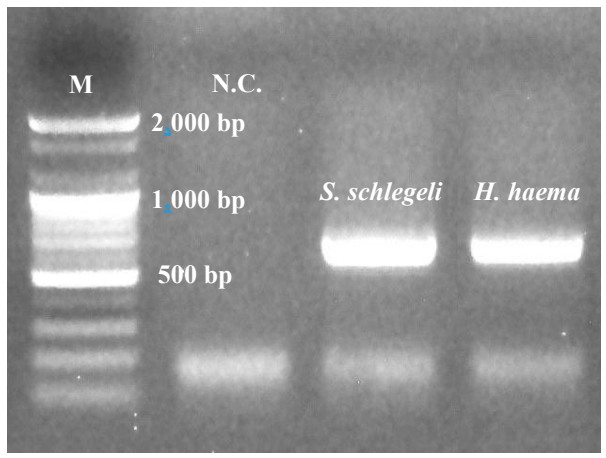

Fig. 5. Electrophoresis results of polymerase chain reaction (PCR) identifying host species and Vibrio splendidus (M $=2,000$ bp marker; N.C. = negative control). PCR results of (A) amplicons of real-time PCR of Vibrio splendidus (150 bp), (B) amplicons of conventional PCR of Vibrio splendidus (550 bp), (C) host species.

ornamental fish market.

In this study, we confirmed that gas bubbles of seahorses could induce secondary $V$. splendidus infection, and lesions showed a gross pathology that was slightly different from that previously reported for lesions (Balcázar et al., 2010). V. splendidus infection could be confirmed from DNA extracted from skin tissues of all seahorse samples, but no infection could be confirmed in internal organs such as kidney and spleen. This is thought to be a secondary infection caused by reduced immunity due to GBD caused by physical or environmental factors, but it is necessary to conduct additional studies on whether
GBD can be caused by infection with $V$. splendidus alone. Because mortality occurred in only one of the several tanks where GBD occurred, and V. splendidus was identified. However, there is a sufficient possibility that this is post-infection after the death of the seahorse. Although environmental problems have a more significant influence, the appropriate use of antibiotics for bacteria identified in vesicular lesions affects the survival rate of the seahorse. This histopathological approach will be of great help in identifying and coping with various pathogens in aquatic ecosystems. Further experiments are needed to confirm the association between V. splendidus and GBD. 


\section{Competing interests}

No potential conflict of interest relevant to this article was reported.

\section{Funding sources}

This research was supported by a 'Development of rapid and sensitive diagnostic methods for the quarantine of aquatic animals, funded by the Ministry of Oceans and Fisheries, Korea.

\section{Acknowledgements}

Not applicable.

\section{Availability of data and materials}

Upon reasonable request, the datasets of this study can be available from the corresponding author.

\section{Ethics approval and consent to participate}

This article does not require IRB/IACUC approval because there are no human and animal participants.

\section{ORCID}

Gyoungsik Kang

Kwang-Min Choi

Min-Soo Joo

Won-Sik Woo

Chan-Il Park

\section{References}

Armada SP, Farto R, Pérez MJ, Nieto TP. Effect of temperature, salinity and nutrient content on the survival responses of Vibrio splendidus biotype I. Microbiology. 2003;149:369-75.

Balcázar JL, Gallo-Bueno A, Planas M, Pintado J. Isolation of Vibrio alginolyticus and Vibrio splendidus from captive-bred seahorses with disease symptoms. Antonie van Leeuwenhoek. 2010;97:207-10.

Bricelj VM, Ford SE, Borrero FJ, Perkins FO, Rivara G, Hillman $\mathrm{RE}$, et al. Unexplained mortalities of hatchery-reared, juvenile oysters, Crassostrea virginica (Gmelin). J Shellfish Res. 1992;11:331-47.

Cao R, Liu Y, Wang Q, Yang D, Liu H, Ran W, et al. Seawater acidification reduced the resistance of Crassostrea gigas to Vibrio splendidus challenge: an energy metabolism perspective. Front Physiol. 2018a;9:880.

Cao R, Wang Q, Yang D, Liu Y, Ran W, Qu Y, et al. $\mathrm{CO}_{2}$-induced ocean acidification impairs the immune function of the Pacific oyster against Vibrio splendidus challenge: an integrated study from a cellular and proteomic perspective. Sci Total Environ. 2018b;625:1574-83.

Gatesoupe FJ, Lambert C, Nicolas JL. Pathogenicity of Vibrio splendidus strains associated with turbot larvae, Scophthalmus maximus. J Appl Microbiol. 1999;87:757-63.

Gómez-León J, Villamil L, Lemos ML, Novoa B, Figueras A. Isolation of Vibrio alginolyticus and Vibrio splendidus from aquacultured carpet shell clam (Ruditapes decussatus) larvae associated with mass mortalities. Appl Environ Microbiol. 2005;71:98-104.

Ivanova NV, Zemlak TS, Hanner RH, Hebert PDN. Universal primer cocktails for fish DNA barcoding. Mol Ecol Notes. 2007;7:544-8.

Jiang F, Huang H, Yang N, Feng H, Li Y, Han B. Isolation, identification, and biological control in vitro of tail rot pathogen strain from Hippocampus kuda. PLOS ONE. 2020;15:e232162.

Lacoste A, Jalabert F, Malham S, Cueff A, Gélébart F, Cordevant C, et al. A Vibrio splendidus strain is associated with summer mortality of juvenile oysters Crassostrea gigas in the Bay of Morlaix (North Brittany, France). Dis Aquat Org. 2001a;46:139-45.

Lacoste A, Jalabert F, Malham SK, Cueff A, Poulet SA. Stress and stress-induced neuroendocrine changes increase the susceptibility of juvenile oysters (Crassostrea gigas) to Vibrio splendidus. Appl Environ Microbiol. 2001b;67:2304-9.

Lambert C, Nicolas JL, Cilia V, Corre S. Vibrio splendidus related strain isolated from brown deposit in scallop (Pecten maximus) cultured in Brittany (France). Bull Eur Assoc Fish Pathol. 1999;19:102-6.

LePage V, Young J, Dutton CJ, Crawshaw G, Paré JA, Kummrow $\mathrm{M}$, et al. Diseases of captive yellow seahorse Hippocampus kuda Bleeker, pot-bellied seahorse Hippocampus abdominalis Lesson and weedy seadragon Phyllopteryx taeniolatus (Lacépède). J Fish Dis. 2015;38:439-50.

Liu R, Chen H, Zhang R, Zhou Z, Hou Z, Gao D, et al. Comparative transcriptome analysis of Vibrio splendidus JZ6 reveals the mechanism of its pathogenicity at low temperatures. Appl Environ Microbiol. 2016;82:2050-61.

Palumbi S. Nucleic acids II: the polymerase chain reaction. In: Hillis D, Moritz C, Mable B, editors. Molecular systematics. Sunderland, MA: Sinauer \& Associates; 1996. p. 205-47.

Pires NMM, Dong T, Yang Z, da Silva LFBA. Recent methods 
and biosensors for foodborne pathogen detection in fish: progress and future prospects to sustainable aquaculture systems. Food Sci Nutr. 2020;61:1852-76.

Reid HI, Treasurer JW, Adam B, Harry Birkbeck T. Analysis of bacterial populations in the gut of developing cod larvae and identification of Vibrio logei, Vibrio anguillarum and Vibrio splendidus as pathogens of cod larvae. Aquaculture. 2009;288:36-43.

Sanaye SV, Pawar HB, Murugan A, Sreepada RA, Singh T, Ansari ZA. Diseases and parasites in cultured yellow seahorse, Hippocampus kuda. Fish Chimes. 2013;32:65-7.

Saulnier D, De Decker S, Tourbiez D, Travers MA. Development of a duplex Taqman real-time PCR assay for rapid identification of Vibrio splendidus-related and V. aestuarianus strains from bacterial cultures. J Microbiol Methods. 2017;140:67-9.

Takahashi S, Tomita J, Nishioka K, Hisada T, Nishijima M. Development of a prokaryotic universal primer for simultaneous analysis of Bacteria and Archaea using next-generation sequencing. PLOS ONE. 2014;9:e105592.

Thompson FL, Iida T, Swings J. Biodiversity of Vibrios. Microbiol Mol Biol Rev. 2004;68:403-31.

Waechter M, Le Roux F, Nicolas JL, Marissal E, Berthe F. Caractérisation de bactéries pathogènes de naissain d'huître creuse Crassostrea gigas. C. R. Biol. 2002;325:231-8.

Zhang Y, Qin G, Lin J, Lin Q. Growth, survivorship, air-bubble disease, and attachment of feeble juvenile seahorses, Hippocampus kuda (Bleeker, 1852). J World Aquac Soc. 2015;46:292-300. 